\section{Promotion of Immature Seed Germination in Jacaranda mimosifolia}

\author{
Ikuo Miyajima, ${ }^{1}$ Adriana Kato, Juan Carlos Hagiwara, Diego Mata, \\ Gabriela Facciuto, Silvina Soto, Alejandro Escandón, Marcela Mori, \\ and Nobuo Kobayashi
}

Instituto de Floricultura, Instituto Nacional de Tecnología Agropecuaria, INTA Castelar, De los Reseros y Las Cabañas s/n. Villa Udaondo Castelar 1712, Buenos Aires, Argentina

Additional index words. Jacaranda mimosifolia, germination, in vitro, immature seed, gibberellic acid

\begin{abstract}
In vitro germination of immature seeds of Jacaranda mimosifolia treated with gibberellic acid $\left(\mathrm{GA}_{3}\right)$ was studied. Immature seeds were collected monthly after crossings and sown on Murashige and Skoog (1962) medium with 3.0\% sucrose and $0.6 \%$ agar after soaked 24 hours with $0,10,100$, and $500 \mathrm{mg} \cdot \mathrm{L}^{-1} \mathrm{GA}_{3}$ solutions. Though germination was observed in the immature seeds harvested 2 months after crossing ( 2 MAC), the rate was quite low. When immature seeds of $3 \mathrm{MAC}$ treated with 100 or $500 \mathrm{mg} \cdot \mathrm{L}^{-1} \mathrm{GA}_{3}$ solution were cultured, $>60 \%$ germination were obtained within 2 weeks after culturing. These results indicate that immature seeds of 3 MAC treated with adequate GA solutions, seedlings can be obtained precociously and the period from crossing to the seedling stage was shorter than for mature seeds.
\end{abstract}

Jacaranda mimosifolia D. Don, native to northwest Argentine and southern Brazil, is one of the most beautiful ornamental trees with attractive lilac-colored flowers (Gentry, 1992). Although this species is favorable for planting along avenue and parks, the utilization of this species is restricted to tropical and subtropical regions because of its poor tolerance to cold climate. Cold hardiness in Jacaranda, therefore, seems to be one of the most important objectives in the breeding of this plant. Since Jacaranda seeds require more than 6 months for maturation after pollination, the long period from crossing to obtaining of the seedlings constitute an obstacle in the cross breeding of this species.

Shortening the period from pollination to the seedling stage was attempted by ovule, ovary or embryo culture in some horticultural plants (Anderson et al., 1990; Torresán et al., 1996; Yasugi, 1984). To obtain seedlings through ovule culture effectively, plant growth regulators are often used (Sharma et al., 1996).

The objectives of this research were to study the effect of gibberellin on immature seeds germination in vitro and to establish a method to shorten the period from crossing to seedling stage in Jacaranda mimosifolia.

Received for publication 15 Dec. 2004. Accepted for publication 23 Jan. 2005. This research was funded by INTA-JICA project 'The Horticulture Development Project in Argentine'. The authors wish to thank Enrique Suarez and Kineo Nishiyama for reviewing this manuscript.

${ }^{1}$ Current address: Institute of Tropical Agriculture, Kyushu University, Fukuoka 812-8581, Japan. Corresponding author; e-mail imiyajima@agr. kyushu-u.ac.jp.

${ }^{2}$ Current address:Lab. Plant breeding, Fac. Life and Environmental Science, Shimane University, Matsue 690-8504, Japan.

\section{Materials and Methods}

The intraspecific crossings among 11 genotypes of Jacaranda mimosifolia with 5 -year-old grafted plants collected from various parts of Argentine were conducted in October 2002 in an unheated greenhouse of the Technological Center on Floriculture, Fruit Culture and Horticulture of Japan International Cooperation Agency (JICA) in Argentina (lat. $34^{\circ} 36^{\prime} \mathrm{S}$; long. $\left.58^{\circ} 40^{\prime} \mathrm{E}\right)$. Flowers for crossings were restricted to four or five in each flower cluster and fresh pollen was used for pollination.

Fruit were collected monthly until 5 months after crossing (MAC). The immature seeds were taken from the fruit that were disinfected by soaking in $70 \%$ ethanol for $5 \mathrm{~min}$ and were soaked with $0,10,100$, and $500 \mathrm{mg} \cdot \mathrm{L}^{-1} \mathrm{GA}_{3}$ solutions for $24 \mathrm{~h}$. After $\mathrm{GA}_{3}$ treatment, the immature seeds were immersed in $1.0 \%$ sodium hypochlorite for 30 min, rinsed three times with sterile distilled water and sown on $20 \mathrm{~mL}$ of culture medium under aseptic conditions. The culture medium was MS (Murashige and Skoog, 1962) with $3.0 \%$ sucrose and $0.6 \%$ agar in $200 \mathrm{~mL}$ culture bottles covered with aluminum foil and autoclaved at $121^{\circ} \mathrm{C}$ for $20 \mathrm{~min}$. Culture was incubated at $25^{\circ} \mathrm{C}$ under $16 \mathrm{~h}$ light with cool-white fluorescent lamps yielding 25 of Jacaranda mimosifolia.

${ }^{2}$ Data were collected after 1 month culture. $5 \%$ level. $\mu \mathrm{mol} \cdot \mathrm{m}^{-2} \cdot \mathrm{s}^{-1}$ PPFD. Four replications using 18 seeds in each treatment were conducted in 1 to 3 MAC immature seeds whereas three replications in 4 and 5 MAC immature seeds. Number of germinated seeds was recorded weekly until 8 weeks after sowing.

\section{Results and Discussion}

Germination was not observed in 1 MAC immature seeds (Table 1). Though germination was observed in 2 MAC immature seeds, the rate was low. Immature seeds of 3 MAC showed $68.2 \%$ and $72.9 \%$ of germination rate after 100 or $500 \mathrm{mg} \cdot \mathrm{L}^{-1} \mathrm{GA}_{3}$ treatment, respectively, whereas the rate was low in 10 $\mathrm{mg} \cdot \mathrm{L}^{-1}$ or without $\mathrm{GA}_{3}$ treatment. There was no significant difference among treatments when 4 MAC immature seeds were used. Since the seeds of 5 MAC showed $>80 \%$ of germination with and without $\mathrm{GA}_{3}$ treatment, it seemed that they have already matured. Germination started one week after sowing and almost completed 2 weeks after sowing (Fig. 1). Almost all seedlings obtained from immature seeds survived after acclimatization and grew vigorously as shown in Fig. 2.

To obtain seedlings through ovule culture effectively, growth regulators are extensively used. Sharma and Gill(1982) reported that a low concentration of auxins is favorable for normal growth, whereas $\mathrm{GA}_{3}$ is more or less effective in the enlargement of the wheat embryos. On the other hand, the effectiveness of $\mathrm{GA}_{3}$ treatment for rapid germination of early harvested ovules was reported in Azalea (Michishita et al., 2001), Malus (Røen, 1994), Helianthus (Torresán et al., 1996). In this investigation, low germination was observed in 2 MAC immature seeds of Jacaranda mimosifolia as the result of $\mathrm{GA}_{3}$ treatment. However, these seedlings could not grow normally and died before acclimatization (Fig. 2). The 3 MAC immature seeds seem to be the required maturity stage for $\mathrm{GA}_{3}$ treatments to be effective.

Jacaranda mimosifolia has a long juvenile phase of about 4 to 5 years before flowering. Therefore, many years might be needed from the beginning of a breeding program to obtain a plant with desirable characteristics. It seems that this is the reason for the lack of reports, presently, on the release of new varieties by cross breeding in this species.

From our results, it was indicated that by exposing immature seeds of 3 MAC of Jacaranda mimosifolia to 100 or $500 \mathrm{mg} \cdot \mathrm{L}^{-1} \mathrm{GA}_{3}$ for $24 \mathrm{~h}$, hybrid seedlings can be obtained precociously and the breeding period of this species might be shortened by this technique.

Table 1. Effect of $\mathrm{GA}_{3}$ treatment on germination of immature seeds obtained from intraspecific crossing

\begin{tabular}{lcrrrr}
\hline $\mathrm{GA}_{3}$ & \multicolumn{5}{c}{ Germination $(\%)^{\mathrm{z}}$} \\
\cline { 2 - 6 }$\left(\mathrm{mg} \cdot \mathrm{L}^{-1}\right)$ & $1 \mathrm{MAC}$ & $2 \mathrm{MAC}$ & $3 \mathrm{MAC}$ & $4 \mathrm{MAC}$ & $5 \mathrm{MAC}$ \\
\hline 0 & $0.0 \mathrm{a}^{\mathrm{y}}$ & $6.4 \mathrm{a}$ & $7.3 \mathrm{a}$ & $38.5 \mathrm{a}$ & $80.3 \mathrm{a}$ \\
10 & $0.0 \mathrm{a}$ & $13.9 \mathrm{a}$ & $20.8 \mathrm{a}$ & $50.4 \mathrm{a}$ & $82.4 \mathrm{a}$ \\
100 & $0.0 \mathrm{a}$ & $6.3 \mathrm{a}$ & $68.2 \mathrm{~b}$ & $69.0 \mathrm{a}$ & $95.8 \mathrm{a}$ \\
500 & $0.0 \mathrm{a}$ & $6.9 \mathrm{a}$ & $72.9 \mathrm{~b}$ & $77.0 \mathrm{a}$ & $93.8 \mathrm{a}$ \\
\hline
\end{tabular}

yifferent letters in the same column indicate significant differences by Duncan's multiple range test at 

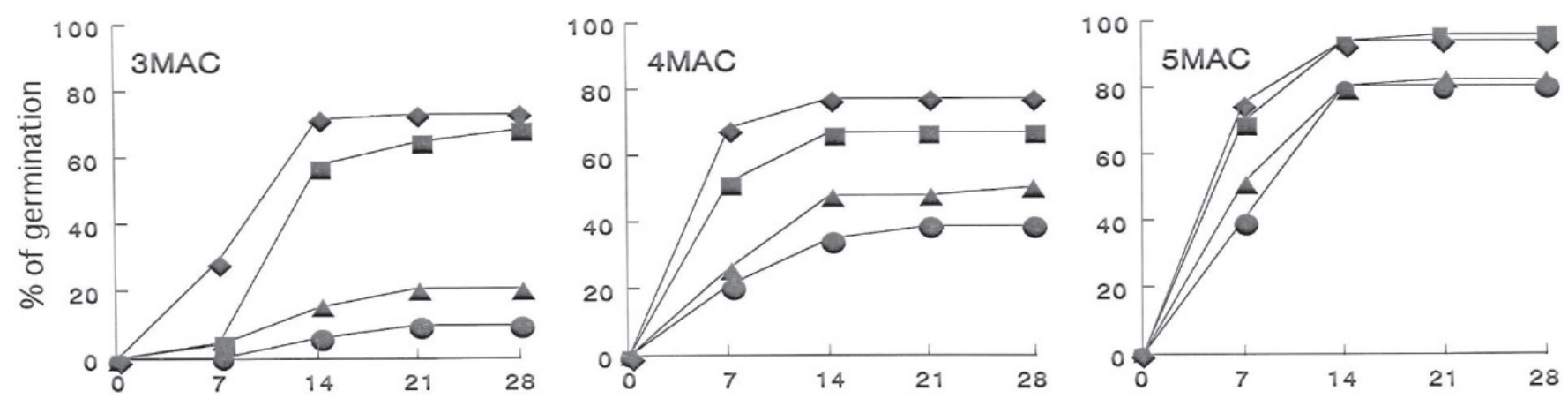

Days after sowing

Fig. 1. Changes in germination rate of immature seeds of Jacaranda mimosifolia sown in vitro. GA level (mg $\left.\cdot \mathrm{L}^{-1}\right): 0=\boldsymbol{\bullet}, 10=\mathbf{\Delta}, 100=\mathbf{\square}, 500=\boldsymbol{\bullet}$.

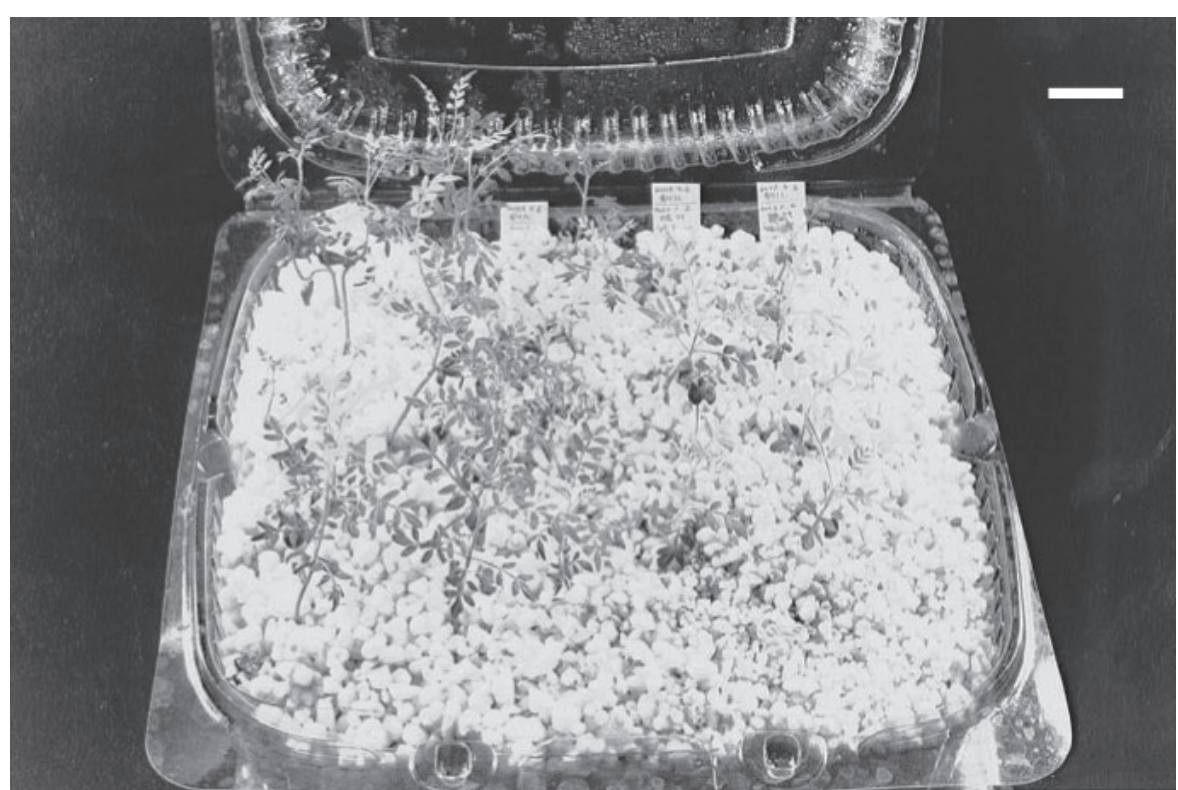

Fig. 2. Acclimatized plantlets obtained from 3 months after crossing (MAC) seeds of Jacaranda mimosifolia. Bar $=20 \mathrm{~mm}$.

\section{Literature Cited}

Anderson, N.O., P.D. Ascher, R.E. Widmer, and J.J. Luby, 1990. Rapid generation cycling of chrysanthemum using laboratory seed development and embryo rescue techniques. J. Amer. Soc. Hort. Sci. 115:329-336.

Gentry, A.H. 1992. Jacaranda, p. 51-105. In: J.L. Luteyn and S.A. Mori (eds.). Flora Neotropica, Bignoniaceae. Part II. The New York Botanic Garden, New York

Michishita, A., K. Ureshino, and I. Miyajima. 2001. Shortening period from crossing to the seedling stage through ovule culture of interspecific crosses of azalea (Rhododendron spp.). J. Jpn. Soc. Hort. Sci. 70(1):54-59.

Murashige, T. and F. Skoog. 1962. A revised medium for rapid growth and bioassays with tobacco tissue cultures. Physiol. Plant 15:473-497.

Røen, D. 1994. Prospects for shortening the breeding cycle of apple (Malus $\times$ domestica Borkh). using embryo culture. I. Reducing the period of cold treatment by hormone application. Gartenbauwissenscaft 59:49-53.

Sharma, D.R., R. Kaur, and K. Kumar. 1996. Embryo rescue in plants-A review. Euphytica 89:325-337.

Sharma, H.C. and B.S. Gill. 1982. Effect of embryo age and culture media on plant growth and vernalization response in winter wheat. Euphytica 31:629-634.

Torresán, A., J. Kesteloot, F. Castaño, R. Rodorígues, and M. Colabelli. 1996. Use of immature seed germination technique as an alternative to in vitro culture of sunflower. (Helianthus annuus L.) embryos. Euphytica 91:1-3.

Yasugi, S. 1984. Shortening the period from pollination to getting seedlings by ovule or ovary culture in Doritis pulcherrima (Orchidaceae). J. Jpn. Soc. Hort. Sci. 53(1):52-58. 